\title{
Use of frozen semen for estimating genetic gains in production traits in pigs
}

\author{
M. MOLENAT *, J. BOULARD **, Geneviève LE HENAFF * \\ * I.N.R.A., Station de Génétique Quantitative et Appliquée, 78350 Jouy-en-Josas \\ ** I.T.P., Service Sélection, B.P. 3, 35650 Le Rheu
}

Frozen semen from 7 Large White and 13 Landrace boars born in 1977 was used in commercial herds of two French districts (Vienne and Deux-Sèvres). Inseminations were mainly made in Large White $\times$ Landrace crossbred females. The 87 piglets sired by Large White boars and the 57 sired by Landrace boars were compared to piglets sired by boars in 1982 for estimating genetic gains.

In the Large White breed, the yearly genetic gain (in p. 100 of the mean) ranged around 2.5 p. 100 for growth performance and 1-4 p. 100 for carcass composition. Meat quality seemed to have slightly deteriorated.

In the Landrace breed, the annual genetic gain was lower : 0.5-1.5 p. 100 for growth performance and about 1 p. 100 for carcass composition. The unfavourable trend in meat quality seemed to be larger than in Large White.

These estimations are more favourable than those of other authors dealing with the same subject in France. These results show that the selection tools developed 20 years ago played a major role in genetic improvement.

\section{A study on the reduction of age of boars at the entry into central performance test stations}

\author{
Michèle DESEINE *, J.P. RUNAVOT *, P. SELLIER **, C. PERROCHEAU*** \\ *I.T.P., B.P. 3, 35650 Le Rheu \\ **I.N.R.A., Station de Génétique Quantitative et Appliquée, 78350 Jouy-en-Josas \\ **: E.D.E. du Morbihan, Station de Sélection Porcine, 56430 Mauron
}

Ranking of boars in central testing stations may be biased by non-genetic differences between herds of origin. A trial was made to determine to what extent the influence of pre-test environment can be reduced by shortening by half the length of the pre-test period, i.e. by lowering the age of male piglets at the arrival into the station by around one month and by rearing them in the same post-weaning unit until 70 days of age. The basic principle of the design consisted of coupling two contemporary batches in two stations: one batch was submitted to the system currently used $(\mathrm{C}=$ entry at about 70 days of age), whereas the other batch was submitted to the new system ( $N=$ entry at about 33 days of age, i.e. just after weaning). Pairs of full sibs were used with one sib on treatment $C$ and the other on treatment $\mathbf{N}$, in order to equalize genetic variances in both treatments. Six « replicates 》 of the comparison between contemporary $\mathrm{C}$ and $\mathrm{N}$ batches were carried out, and a total of 409 pairs of littermates from 342 sires were included in the analysis. There was no effect of treatment on age at $35 \mathrm{~kg}$ and ultrasonic backfat thickness at $90 \mathrm{~kg}$. However, boars submitted to treatment $\mathrm{N}$, as compared to those submitted to treatment $\mathrm{C}$, exhibited higher daily gain on test (948 vs $924 \mathrm{~g}$ from 35 to $90 \mathrm{~kg}$ ), improved food conversion ratio (2.56 vs 2.61) better health status and lower rates of culling for constitutional disorders. Some decrease in within-batch phenotypic variance was observed in daily gain on test with treatment $\mathrm{N}$. The percentage of variance due to the herd of origin was estimated for each 